\title{
Assessment and Management of Diabetic Patients During the COVID-19 Pandemic
}

\author{
Amit K Verma' \\ Mirza Masroor Ali Beg ${ }^{2}$ \\ Deepti Bhatt' \\ Kapil Dev' \\ Mohammed A Alsahli ${ }^{3}$ \\ Arshad Husain Rahmani ${ }^{3}$ \\ Yamini Goyal' \\ 'Medical Biotechnology Lab, Department \\ of Biotechnology, Jamia Millia Islamia, \\ New Delhi, India; ${ }^{2}$ Department of \\ Biochemistry, Maulana Azad Medical \\ College, New Delhi, India; ${ }^{3}$ Department \\ of Medical Laboratories, College of \\ Applied Medical Sciences, Qassim \\ University, Buraydah, Saudi Arabia
}

Correspondence: Yamini Goyal

Medical Biotechnology Lab, Department

of Biotechnology, Jamia Millia Islamia,

Srinivasa Ramanujan Block, Mujeeb Bagh,

New Delhi, I I0025, India

Email yaminil88673@st.jmi.ac.in

\begin{abstract}
COVID-19 has become a great challenge across the globe, particularly in developing and densely populated countries, such as India. COVID-19 is extremely infectious and is transmitted via respiratory droplets from infected persons. DM, hypertension, and cardiovascular disease are highly prevalent comorbidities associated with COVID-19. It has been observed that COVID-19 is associated with high blood-glucose levels, mainly in people with type 2 diabetes mellitus (T2DM). Several studies have shown DM to be a significant risk factor affecting the severity of various kinds of infection. Dysregulated immunoresponse found in diabetic patients plays an important role in exacerbating severity. DM is among the comorbidities linked with mortality and morbidity in COVID-19 patients. Chronic conditions like obesity, cardiovascular disorders, and hypertension, together with changed expression of ACE2, dysregulated immunoresponse, and endothelial dysfunction, may put diabetic patients at risk of greater COVID-19 severity. Therefore, it is important to study specific characteristics of COVID-19 in diabetic people and treat these comorbidities along with COVID-19 infection, mainly among old individuals who are already suffering from serious and critical infections. This review will be helpful in understanding the mechanisms involved in COVID19 and DM, the role of ACE2 in COVID-19 pathogenesis, management of DM, and associated complications in COVID-19 patients.
\end{abstract}

Keywords: COVID-19, diabetes, hypertension, cardiovascular diseases, India

\section{Introduction}

SARS-CoV2 causes COVID-19. ${ }^{1}$ It is an enveloped virus and has ssRNA, which generally infects the upper respiratory tract in humans. ${ }^{2}$ COVID-19 is highly contagious and is transmitted via respiratory droplets from infected persons. ${ }^{3}$ It enters the human body via upper respiratory mucous membrane and thereafter affects the lungs. ${ }^{4}$ In most cases, COVID-19 infection is a minor disease; however, some individuals develop serious characteristics of infection through compromised respiratory function $\left(\mathrm{SpO}_{2}<93 \%\right.$; pulmonary infiltrate, $>50 \%$ of lung field during radiology, respiration rate $\geq 30$ breaths per minute, $\left.\mathrm{PaO}_{2}: \mathrm{FiO}_{2}<300\right)$. ${ }^{5}$ Few people have developed dangerous or life-threatening coronavirus infection through multiple-organ failure. ${ }^{6}$ Information related to COVID-19 patients has suggested that most of them had comorbidities. Diabetes (DM), hypertension, and cardiovascular disease (CVD) are highly prevalent comorbidities associated with COVID-19. Data from COVID-19 patients have revealed that COVID-19 is linked with high bloodglucose level, mainly in people with type 2 DM (T2DM). ${ }^{7}$ Due to high DM prevalence, it is very important to study specific characteristics of SARS-CoV2 in diabetic people. ${ }^{8}$ 
Several studies have also reported that immunocompromised COVID-19 patients, including those with HIV, pregnant women, and cancer patients, could be at higher risk of severe COVID-19 symptoms. ${ }^{9-12}$ Nations with high HIV-infection rates, such as India and South Africa, tend to have more COVID-19 patients. ${ }^{11}$ Sahu et al suggested that COVID-19 infection in pregnant patients requires extra management with special care. ${ }^{12}$ The UK National Health Service found that some groups, including blood cancer patients and those undergoing radio- or chemotherapy for lung cancer, were particularly susceptible to severe COVID-19 infection. ${ }^{10}$

At the time of writing, COVID-19 cases are increasing day by day with $>91$ million confirmed cases, $1,986,871$ deaths worldwide, ${ }^{13}$ and $>10.5$ million confirmed cases with 151,918 deaths in India. ${ }^{14}$ In 2019 , around 77 million were living with DM in India, and this number will increase to 101 million by 2030 and 134.2 million by 2045. After China, India has the secondhighest number of diabetic patients across the globe. ${ }^{15} \mathrm{In}$ India, about 12.1 million people aged $\geq 65$ years had DM in 2019. ${ }^{16}$ According to an International DM Federation report, India had the greatest number of children and adolescents (age 0-14 years) living with type $1 \mathrm{DM}$ in 2019. There are around $15.9,000$ new type 1 DM cases reported annually in children and adolescents. ${ }^{16}$ T1DM and T2DM are two types of DM. ${ }^{17}$ Both types intensify the risk and complications related to the infection. ${ }^{18,19}$ Viral and bacterial diseases in the respiratory system are common infections associated with DM, and disrupted humoral immunoresponse, neutrophil dysfunction, and decreased T-lymphocyte responses contribute to the infection. ${ }^{5,20}$ Increase risk of mortality and morbidity after pneumonia is linked with DM, and people with high blood glucose $(>200 \mathrm{mg} / \mathrm{dL}$ ) have more pneumonia complications than those with normal glucose levels. ${ }^{21,22}$ At the time of the SARS epidemic (2002-2003), DM remained an autonomous interpreter of risk of mortality (OR 3, 95\% CI 1.40-6.30; $p=0.005) .{ }^{23}$ During the MERSCoV epidemic (2012), comorbidities like DM influenced the risk of mortality (adjusted HR 3.74 per year, 95\% CI $2.57-5.56) .{ }^{24}$ Studies also reported that among all comorbidities, DM had the greatest influence on risk of mortality in people with MERS-CoV. ${ }^{25}$ Furthermore, similar results were observed during H1N1 infection (2009), where DM intensified intensive care unit (ICU) admission of young patients with H1N1 (OR 4.72, 95\% CI 1.81-12.3). ${ }^{26}$ In this review, we discussed the mechanisms involved in
COVID-19 and DM, the role of ACE2 in COVID-19 pathogenesis and management of $\mathrm{DM}$, and associated complications in COVID-19 patients.

\section{COVID-I 9 Characteristics}

Incubation Time

The period between infectivity and onset of disease is known as incubation time. A study involving 1,099 people infected with COVID-19 reported that average incubation time for symptomatic SARS-CoV2 was 4 days. ${ }^{27}$ Another study on 181 COVID-19 patients from China confirmed an average incubation time of 5 days for SARS-CoV2, and in $97.5 \%$ of patients, symptoms of infection developed within 12 days. ${ }^{28}$ On the basis of the incubation time of SARS-CoV and MERS-CoV, the US Centers for Disease Control and Prevention (CDC) projected that COVID-19 symptoms would arise2-14 after infection. As such, 14 days (quarantine) is the period used for examining and limiting the movement of individuals at risk. ${ }^{29}$

\section{Modes of Transmission}

Most of the original people infected with COVID-19 had a history of direct contact with a wholesale market for wildlife and seafood in China, signifying the exposure of zoonotic virus as a major transmission mode of COVID-19. ${ }^{30}$ Analysis of virus-sequencing data revealed that COVID19COVID-19 found in bats and SARS-CoV2 may have a common ancestor, though this Chinese wholesale market does not sell bats. ${ }^{31}$ After some time, COVID-19 infections were found in health-care personnel and other individuals with no contact with wildlife or travel history in Wuhan, China, indicating individual-to-individual transmission or spread of COVID-19. ${ }^{30}$ Numerous studies have suggested that SARS-CoV2 could be transmitted via aerosols, drops, and direct contact with infected persons (Figure 1). Respiratory drops spread infection from one individual to another through sneezing and coughing. This happens because respiratory drops from an infected individual get into the air and are inhaled by healthy individuals nearby (within $2 \mathrm{~m}$ ). Individuals can get COVID-19 infection via contacting contaminated objects or surfaces infected with COVID-19 and then touching their eyes, mouth, or nose. ${ }^{32}$ Studies have revealed that COVID-19 can stay viable within aerosols for up to 3 hours and spread in a closed system if inhaled breathed into the respiratory tract. ${ }^{32,33}$ As such, transmission of COVID-19 through the air has been made possible due to aerosol-producing processes like cardiopulmonary 


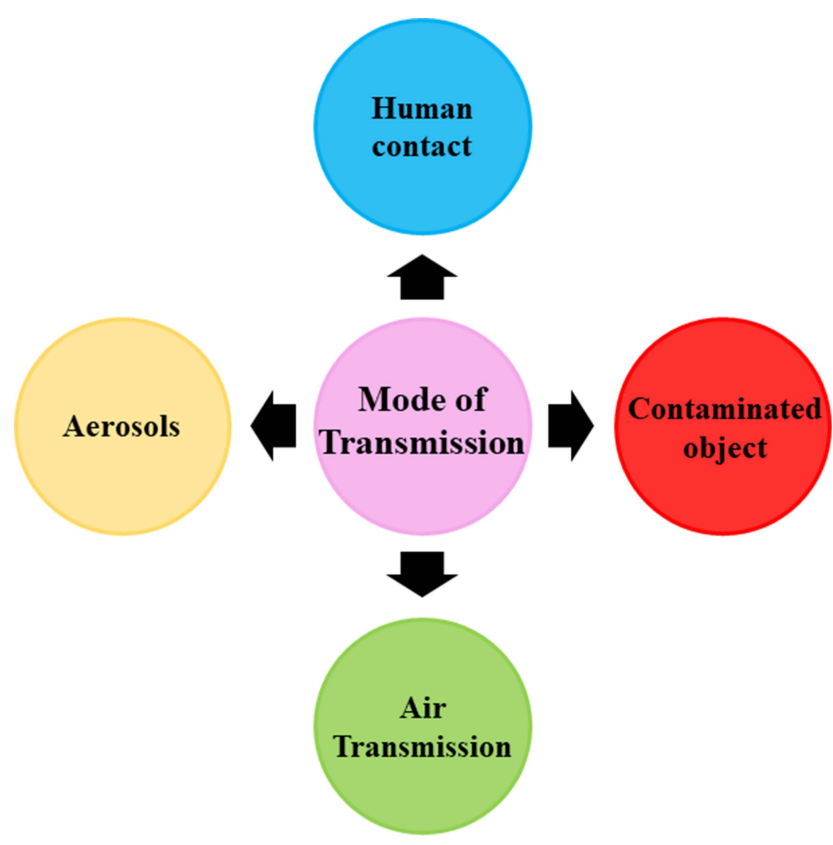

Figure I Mode of transmission of novel COVID-19.

resuscitation, bronchoscopy, tracheostomy, endotracheal intubation, and noninvasive positive-pressure ventilation. ${ }^{13}$

\section{Pathogenesis}

SARS-CoV2 infection can be differentiated into three phases: phase 1 is the initial infection stage, phase 2 the pulmonary stage, and phase 3 the hyperinflammation stage. ${ }^{34,35}$ In the early phase of infection, patients show symptoms like headache, fever, and dry cough. Clinical signs involve increased lymphopenia, high IL6, D-dimer, and prothrombin, and mild level of lactate dehydrogenase. In the pulmonary stage, some patients show abnormal chest images, breathlessness, and increased levels of transaminases. In the more serious stage, some develop cytokine storm, which leads to other complications involving shock, multiorgan failure, acute respiratory distress syndrome, and death. Elevated clinical inflammatory markers, such as lactate dehydrogenase, ferritin, D-dimer, IL6, troponin, CRP, and N-terminal (pro-brain natriuretic peptide are hallmarks of this stage. These results are in line with MERS and SARS in that the incidence of cytokine storm and lymphopenia may play an important role in COVID-19 pathogenesis. ${ }^{36-38}$ Therefore, disease intensity in COVID-19 patients is due both to the virus and the response of the host. ${ }^{39}$

\section{Infectivity Period}

It is not known how long it takes for a COVID-19 patient to recover from infection. The infectivity period is estimated by detecting the virus or its ssRNA in respiratory tract samples. Though, presence of ssRNA of virus does not approve the contagious virus occurrence. Reports suggest that transmission of the virus may occur in the early stage of COVID-19 infection, as high virus loads are found in respiratory samples shortly after the onset of symptoms. ${ }^{40}$ The period of shedding of the virus changes with the seriousness of the infection. About $90 \%$ of COVID-19 individuals with mild symptoms show an absence of virus or give negative tests on nasal swabs after 10 days of onset of infection, whereas in serious and critical cases, nasal swabs are positive. ${ }^{41}$ Studies have also revealed that the virus load found in asymptomatic individuals was similar to the virus load found in symptomatic patients. ${ }^{40}$

\section{Diagnosis}

To manage COVID-19 outbreaks in communities and hospitals, several diagnostic tests have been utilized. Realtime fluorescence-based quantitative PCR is considered the standard test for diagnosis of COVID-19. In this method, ssRNA of COVID-19 is detected in respiratory swabs, lower respiratory secretions, and sputum. ${ }^{29,42}$

\section{RT-PCR Test}

Real-time PCR is an important and widely used method for diagnosis of COVID-19 where RNA is converted into cDNA using reverse transcriptase, which is quantified using different primer sets, as recommended by the World Health Organization and using RNAse $\mathrm{P}$ as an internal control. ${ }^{43}$ Different regions in the genome have been identified, which has served as the template for primer design, with primers targeting $\mathrm{E}$ gene, $\mathrm{N}$ gene, and RNA replicase or RdRp possessing the highest sensitivity. ${ }^{43,44}$ Beside this, a number of multiplex assays have been developed that can target multiple genes together, eg, RdRp/Hel, S, and N. ${ }^{45}$ Multiplexing offers improved sensitivity in cases of degraded virus-RNA samples and development of putative mutations, with sensitivity $>95 \%$. However, false-positive tests might be obtained through primer cross-reactivity with other coronaviruses like SARS-CoV. ${ }^{46}$

The isothermal method does not requires thermal cycling as a conventional RT and amplifies DNA at a particular temperature, but delivers sensitivity similar to PCR. ${ }^{46}$ Variations of isothermal amplification have been developed, such as $\mathrm{HAD},{ }^{47} \mathrm{NASBA}^{48}{ }^{4 A M P},{ }^{46}$ SDA, ${ }^{49}$ and RPA. ${ }^{50}$ RT-LAMP uses four to six pairs of primers corresponding to distinct regions in the genome, 
which imparts the assay very high specificity. ${ }^{51-53}$ This test involves an SD polymerase and primer binding, as well as amplification, and occurs at $60^{\circ}-65^{\circ} \mathrm{C}$. The reaction occurs in a single Eppendorf tube, and the DNA product is identified through its turbidity, color, or fluorescence, depending on the type of reagent added. ${ }^{54}$ The assay offers several advantages, such as ease of operation, less background signal, and higher sensitivity, in comparison to conventional RT-PCR. ${ }^{51}$ However, its major drawback is the requirement for extensive optimization of the primers. RT-LAMP can be multiplexed using polymeric beads with unique signatures and barcodes, ${ }^{55}$ which increases the amount of information gained through a single reaction. ${ }^{56}$ Multiplexing allows us to measure different biomarkers in a single reaction with improved specificity and sensitivity. These barcoded bead-based assays still need thorough optimization before being introduced into the clinical setup. However, barcoded beadbased assays are still available for the diagnosis of cystic fibrosis and respiratory diseases. ${ }^{57}$

\section{Rapid Antigen-Detection Test}

This test can qualitatively determine the occurrence of COVID-19 antigen and provide results in much less time, which provides the opportunity for better management of the disease. However these tests suffer from poor sensitivity, as observed with influenza viruses. ${ }^{58-61}$

ELISAs can detect specific antibodies among respiratory and blood samples of an infected person. Antibody-mediated immunity against virus can be determined by measuring generated $\operatorname{IgG}$ and $\operatorname{IgM}$. IgM is produced on the basis of the initial humoral response against the virus, while IgG is produced after 7 days of infection and stays thereafter, mediating the acquired immunoresponse. ${ }^{62,63}$ Detection of COVID-19 in patients by detecting the antigen is difficult compared to other developing methods that identify NAbs, as it requires production of purified monoclonal antibodies.

Immunodetection can also be used in identifying recovered patients whose convalescent plasma can be utilized for the treatment of critical patients. ${ }^{64}$ Proteins that mediate virus entry into host cells by interacting with ACE2 receptor are the key target for developing diagnostic antibodies. ${ }^{65}$ Other targets include the $\mathrm{N}$ protein and virally encoded repressor. ${ }^{66}$ ELISAs are an easy and appropriate method for rapid recognition of antibodies generated against COVID-19 in a short period in the same patient. Receiver-operating characteristic analysis has revealed that the sensitivity of IgG- and IgMbased ELISAs $88.9 \%$ and $48.1 \%$, respectively, whereas specificity was $90.9 \%$ and $100 \%$. The lower sensitivity associated with $\operatorname{IgM}$ is due to the fact that the response occurs early and then gradually decreases with time, ${ }^{67}$ which can be improved by the incorporation of novel labels like gold-labeled Ig. ${ }^{68}$

\section{Comorbidities Associated with COVID-19}

Many studies have revealed that life-threatening and critical cases of COVID-19 are found among old patients or in persons with comorbidities, specifically DM, hypertension, CVD,cancer, and chronic renal and lung disorders. ${ }^{27,37,38,69}$ Table 1 shows the prevalence of comorbidities among COVID-19 patients. ${ }^{8}$ One meta-analysis from China on 1,527 infected individuals reported that the highly prevalent comorbidities associated with SARS-CoV2 were hypertension (17.1\%, 95\% CI 9.9-24.4), DM (9.7\%, 95\% CI 6.9-12.5) and cerebrovascular disorders $(16.4 \%, 95 \%$ CI $6.6-26.1)$. This metaanalysis showed that COVID-19-infected people with hypertension or DM had double the severity of infection or ICU admission, whereas patients with cerebrovascular disorders showed triple the disease severity. ${ }^{36}$ A comprehensive review and meta-analysis reported that older age and associated comorbidities, such as DM, hypertension, heart disorder, chronic obstructive pulmonary disease (COPD), chronic kidney disease), and chronic liver disease enhanced the risk of progression to critical disease and death among COVID-19 patients. ${ }^{70}$ Moreover, it has been observed that COVID-19 causes more neurological complications than MERSCoV aor SARS-CoV. ${ }^{71}$ A comprehensive evaluation reported that hypertension is more common than T2DM in patients with COVID-19. ${ }^{72}$ Another study reported that blood type influenced prognosis in COVID-19 patients with hypertension. ${ }^{73}$ A study conducted on COVID-19 patients with hypertension found significantly higher values on prothrombotic indices and high rates of cardiac damage and mortality in non-O blood-group patients in comparison with Oblood-group patients. This study also suggested that endothelial dysfunction level in non-O blood-group patients can be increased by prothrombotic status. ${ }^{73}$ Lip reported that endothelial dysfunction in patients with hypertension can trigger stroke and cardiac injury through thromboembolism. ${ }^{74}$ It has been recommended that modified immune-system, antiinflammatory, and anti-hypertensive treatments may inhibit poorer prognosis and increase clinical consequences in hypertensive patients with COVID-19. ${ }^{75}$ Furthermore, antihypertensive drug treatment, including ACEIs and ARBs did not 
Table I Prevalence of comorbidities among COVID-19 patients

\begin{tabular}{|c|c|c|c|c|c|c|c|c|c|c|}
\hline Source & Region & $\begin{array}{c}\text { Subjects, } \\
n\end{array}$ & $\begin{array}{l}\text { DM } \\
(\%)\end{array}$ & $\begin{array}{c}\text { Smokers } \\
(\%)\end{array}$ & $\begin{array}{c}\text { CKD } \\
(\%)\end{array}$ & $\begin{array}{c}\text { COPD } \\
\text { (\%) }\end{array}$ & $\begin{array}{c}\text { CLD } \\
(\%)\end{array}$ & $\begin{array}{l}\text { Htn } \\
\text { (\%) }\end{array}$ & $\begin{array}{c}\text { CVD } \\
(\%)\end{array}$ & Reference \\
\hline CCDCP & China & 20,982 & 5.3 & - & - & 2.4 & - & 12.8 & 4.2 & 152 \\
\hline Liu et al & China & 61 & 8.2 & 6.6 & - & 8.2 & - & 19.7 & 1.6 & 153 \\
\hline Gupta et al & India & 21 & 14.2 & - & - & 0 & - & - & 0 & 80 \\
\hline Chen et al & China & 274 & 17.0 & 7.0 & 1.0 & 7.0 & - & 34.0 & 8.0 & 154 \\
\hline Guan et al & China & 1099 & 7.4 & 12.6 & 0.7 & 1.1 & - & 15.0 & 3.8 & 27 \\
\hline Zhou et al & China & 191 & 19.0 & 6.0 & 1.0 & 3.0 & - & 30.0 & 8.0 & 38 \\
\hline Huang et al & China & 41 & 19.5 & 7.3 & - & 2.4 & 2.4 & 14.6 & 15.0 & 82 \\
\hline Zhang et al & China & 140 & 12.1 & - & 1.4 & 1.4 & - & 30.0 & 8.6 & 155 \\
\hline Chen et al & China & 99 & 12.1 & - & - & 1.0 & & - & 40.0 & 156 \\
\hline Yang et al & China & 52 & 17.0 & 4.0 & - & 8.0 & - & - & 23.0 & 157 \\
\hline Wang et al & China & 138 & 10.1 & - & 2.9 & 2.9 & 2.9 & 31.2 & 19.6 & 35 \\
\hline Wu et al & China & 201 & 10.9 & - & 1.0 & 2.5 & 3.5 & 19.4 & 4.0 & 158 \\
\hline Liu et al & China & 137 & 10.2 & - & - & 1.5 & - & 9.5 & 7.3 & 159 \\
\hline Guo et al & China & 187 & 15.0 & 9.6 & 3.2 & 2.1 & - & 32.6 & 11.2 & 160 \\
\hline CDC COVID-19 Response Team & USA & 7162 & 10.9 & 3.6 & 3.0 & 9.2 & 0.6 & - & 9.0 & 161 \\
\hline Bhatraju et al & USA & 24 & 58.0 & 22.0 & 21.0 & 4.0 & - & - & - & 162 \\
\hline COVID-19 Surveillance Group & Italy & $48 I^{*}$ & 33.9 & - & 20.2 & 13.7 & 3.7 & 73.8 & 30.1 & 88 \\
\hline Onder et al & Italy & 355 & 35.5 & - & - & - & - & - & 42.5 & 81 \\
\hline
\end{tabular}

Notes: *Deaths from COVID-19. Data from Singh et al. ${ }^{8}$

Abbreviations: CCDCP, Chinese Center for Disease Control and Prevention; CKD, chronic kidney disease; CLD, chronic liver disease; Htn, hypertension; CVD, cardiovascular disease; CDC, Centers for Disease Control and Prevention; COPD, chronic obstructive pulmonary disease.

influence the prognosis among patients with COVID-19. As a result, it was suggested that hypertensive patients with COVID-19 infection undergoing antihypertensive drug therapy should continue their treatment to manage hypertension and prevent severe complications. ${ }^{75}$ Several studies have identified stroke in COVID-19 patients. ${ }^{71,76-78}$ Mechanisms involving endothelial dysfunction and immunomediated injury cause stroke and lead to hypoxia-induced injury and cytokine storm. $^{71}$ Yang et al reported that chronic kidney-disease patients with COVID-19 exhibited poor prognosis, high prevalence of neutrophilia, and in-hospital deaths and also that dialysis patients are more susceptible to COVID-19 infection. ${ }^{79}$ A study from India reported that $14.2 \%$ of 21 COVID-19 patients had DM. ${ }^{80}$ Of 355 COVID-19-infected people who expired in Italy, only three were had no comorbidities. ${ }^{81}$ A couple of studies have revealed that along with the lungs, SARS-CoV2 can also harm the kidneys, heart, and/or liver. ${ }^{35,82}$ There is a need to treat these comorbidities along with COVID-19 infection, especially among old-age individuals who already have serious and critical infections.

\section{COVID-I 9 and Diabetes}

\section{Mechanisms and Common Factors}

DM is a major cause of morbidity and mortality across the globe. This disease is linked with numerous complications that affect disease severity. ${ }^{83}$ Diseases like pneumonia and influenza commonly found in old people with T2DM. ${ }^{84,85}$ Studies have reported that high blood glucose and DM play a vital role in death and severity of infection in individuals with infectious virus, such as MERS-CoV, H1N1 (influenza A), and SARS-CoV. ${ }^{23,86,87}$ Several studies have reported that people with diseases like DM and CVD are at greater risk of serious and critical illness from COVID-19. ${ }^{27,81,88}$ Chen et al also observed that older diabetic patients were more susceptible to death due to COVID-19. They reported that COVID19 infection in diabetic patients was associated with higher CRP and older age. ${ }^{89}$ COVID-19 disease in diabetic people may trigger excessive stress and high secretion of hyperglycemia-related hormones like catecholamine and glucocorticoid. These hormones cause irregular variability of glucose in blood and increase blood-glucose (Figure 2). ${ }^{90}$

Resistance of insulin and high blood glucose encourages production of oxidative stress inhibits the production of glycosylation and proinflammatory cytokines. It also influences the synthesis of adhesion molecules, which facilitate tissue inflammation. The process of inflammation comprises an underlying system that increases tendency toward infection and results in serious and life-threatening consequences in diabetic patients with COVID-19. ${ }^{91-93}$ Uncontrolled or poorly managed DM has been found to be 


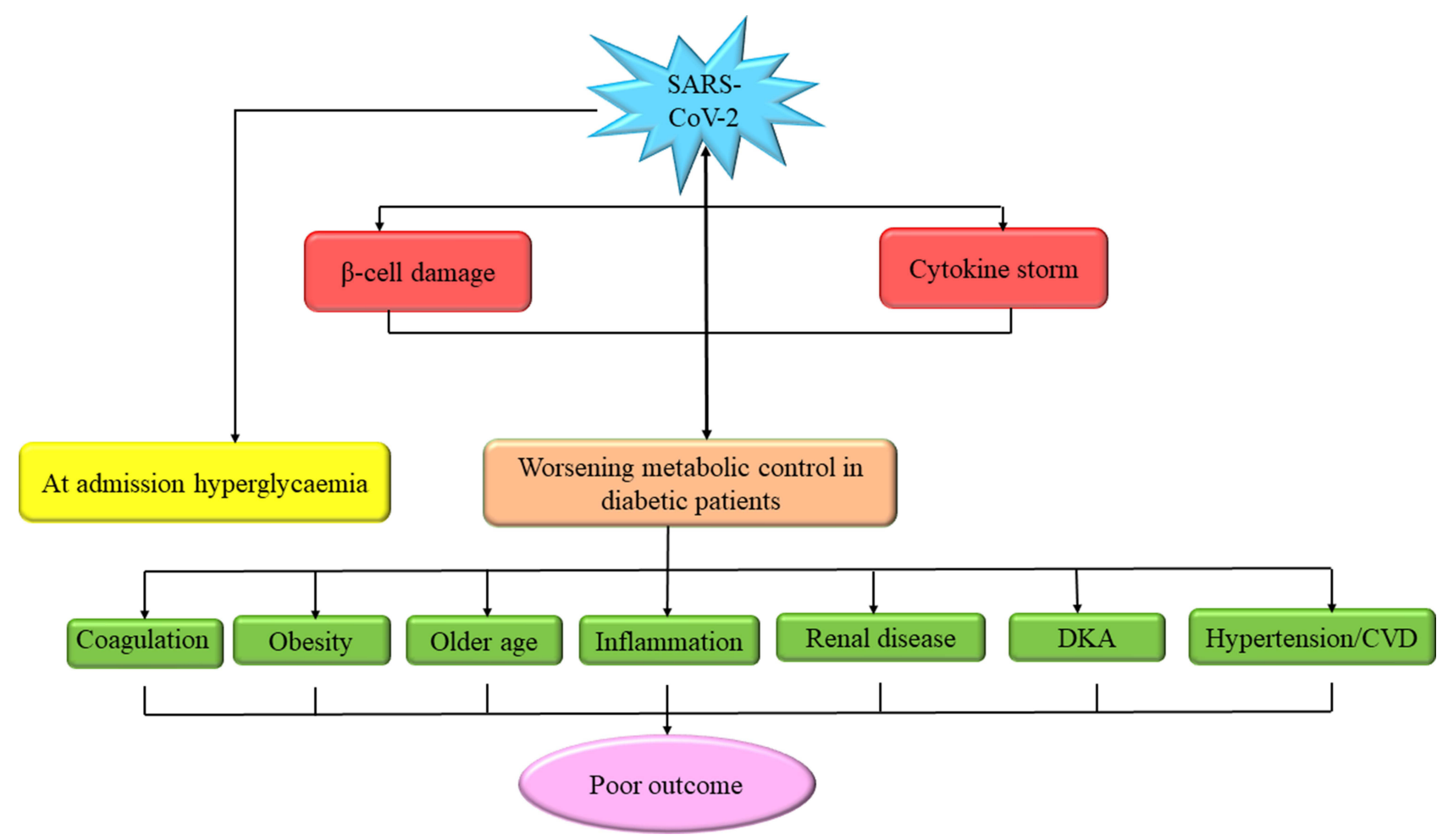

Figure 2 Reciprocal effects of COVID-19 and DM. Diabetic patients with COVID-19 infection facesevere consequences due to various associated conditions that enhance the risk. Due to its tropism for $\beta$-cells, SARS-CoV2 may sustain xhyperglycemia at admission to hospital. $\beta$-cell damage, cytokine storm, and counterregulatory hormone response may cause critical metabolic disorders, such as DKA. Hyperglycemia at admission and critical metabolic disorders may exacerbate COVID-19 consequences. Note: Data from Apicella et al. ${ }^{93}$

Abbreviations: CVD, cardiovascular disease; DKA, diabetic ketoacidosis.

associated with reduced lymphocyte-proliferative responses to different stimuli and also decreased function of neutrophils and macrophages. ${ }^{92}$ Raoufi et al study showed that chest-severity scores and clinical outcomes were alike in COVID-19 patients with well-controlled DM and poorly controlled DM in an Iranian population. ${ }^{94}$ Dysfunctional activation of complement and irregular delayed hypersensitivity have been observed in diabetic people. ${ }^{95,96}$

\section{Dysregulated Immunoresponse and Cytokine Storm} Diabetic patients have chronic low-level inflammation, leading to exaggerated monocyte, macrophage, and T-cell recruitment, thereby promoting inflammation in a feedback loop. Excess production of proinflammatory cytokines may ultimately damage the infrastructure of the lungs. As a result, cytokine storm may activate the coagulation system. In all types of viral infections, effective clearance of virus load strongly depends upon the combined action of adaptive and innate immunity. ${ }^{39}$ High blood glucose may repress the antiviral response. ${ }^{97}$ It has been observed that diabetic patients undergo changes in components of innate immunity. For instance, primary cell events to identify and destroy pathogens like phagocytosis and chemotaxis are impaired in diabetic patients. ${ }^{98,99}$ More proinflammatory M1 macrophages are present among T2DM patients, whereas natural killer-cell activity is reduced in patients with DM. ${ }^{100,101}$ Moreover, activity of $\mathrm{T}$ cells is distorted. Diabetic patients are in a low chronic proinflammatory phase with $\mathrm{T}_{\mathrm{H}} 1-\mathrm{T}_{\mathrm{H}} 2$ imbalance. ${ }^{102,103}$ Irrespective of endothelial cell participation, primary delay in response of IFN $\gamma$, along with hyperinflammatory responses in diabetic patients may worsen the cytokine storm and increase the severity of COVID-19 infection. ${ }^{39}$

\section{Endothelial Dysfunction}

Virus infection induces pyroptosis and is related to inflammation and vascular injury, as seen in SARS-CoV patients. $^{104}$ It has been observed that destruction by COVID-19, MERS, and SARS is not restricted to the lungs only, appearing in other organs, such as the kidneys and heart, which suggests that SARS-CoV2 can infect blood vessels and spread to other body organs. ${ }^{105}$ Monteil et al showed that SARS-CoV2 can directly infect 
vascular endothelial cells in engineered human capillary organoids. ${ }^{106}$ Another study demonstrated the occurrence of viral accumulation and elements of inflammatory cells in the blood vessels of patients with COVID-19. ${ }^{107}$ These studies suggest that SARS-CoV2 infection may induce endothelial inflammation among other organs and that pyroptosis may play a key role in host inflammatory responses and endothelial cell damage. High blood pressure, kidney disorders, DM, venous and arterial thromboembolism, and neurological diseases in COVID-19 patients signify that SARS-Cov- 2 affects the endothelium. ${ }^{72}$ Endothelial dysfunction is associated with microvascular complications in patients with T1DM or T2DM. ${ }^{108}$

\section{Diabetes, SARS-CoV2, and ACE2}

The receptor-binding domain of SARS-CoV2 uses host-cell ACE2 to bind membranes of host cells and virus. ${ }^{109}$ ACE2, type 1 glycoprotein, is abundantly expressed in the lungs, kidneys, heart and endothelium. ${ }^{110}$ ACE2 upregulation provides more receptors for entry of viruses and causes more viruses to enter host cells. ${ }^{111}$ ACE2 transforms angiotensinogen I into angiotensinogen (1-9) and angiotensinogen II into angiotensinogen (1-7) (Figure 3). These have cardioprotective and anti-inflammatory effects, and later function as vasodilators. Under normal circumstances, many studies have demonstrated reduced expression of ACE2 in lung cells and tissue. ${ }^{112,113}$ However, injury in lungs upregulates ACE2 expression. Studies on human and animal subjects have reported that ACE2 can be used as a therapeutic agent in the treatment of inflammatory acute lung injury. ${ }^{114,115}$ Moreover, SARS-CoV seems to downregulate the expression of ACE2 in virus-infected cells. ${ }^{116}$

People infected with SARS in 2003 showed high blood glucose in comparison to patients with pneumonia without SARS infection, regardless of premorbid blood-glucose levels or disease severity. ${ }^{5}$ Consequently, SARS-CoV combined with ACE2 in islet cells of the pancreas and injures them, which increases blood glucose. It also contributes to increased mortality rates in patients with/without DM. ${ }^{117}$ A similar process may occur in SARS-CoV2 infection and contribute to high blood glucose and related complications, as well as a high rate of mortality. Though few features of ACE1 and ACE2 are similar, but ACEIs does not inhibit ACE2. ${ }^{118}$ The expression of ACE2 is upregulated by ARBs and ACEIs. As such, ARBs or ACEIs may help SARS-CoV2 infection, which leads to disease severity. ${ }^{119}$ Moreover, polymorphism in the $A C E 2$ gene is associated with elevated DM and CVD risk, which can cause vulnerability to COVID-19, whereas upregulation of ACE2 increases angiotensinogen (1-7)

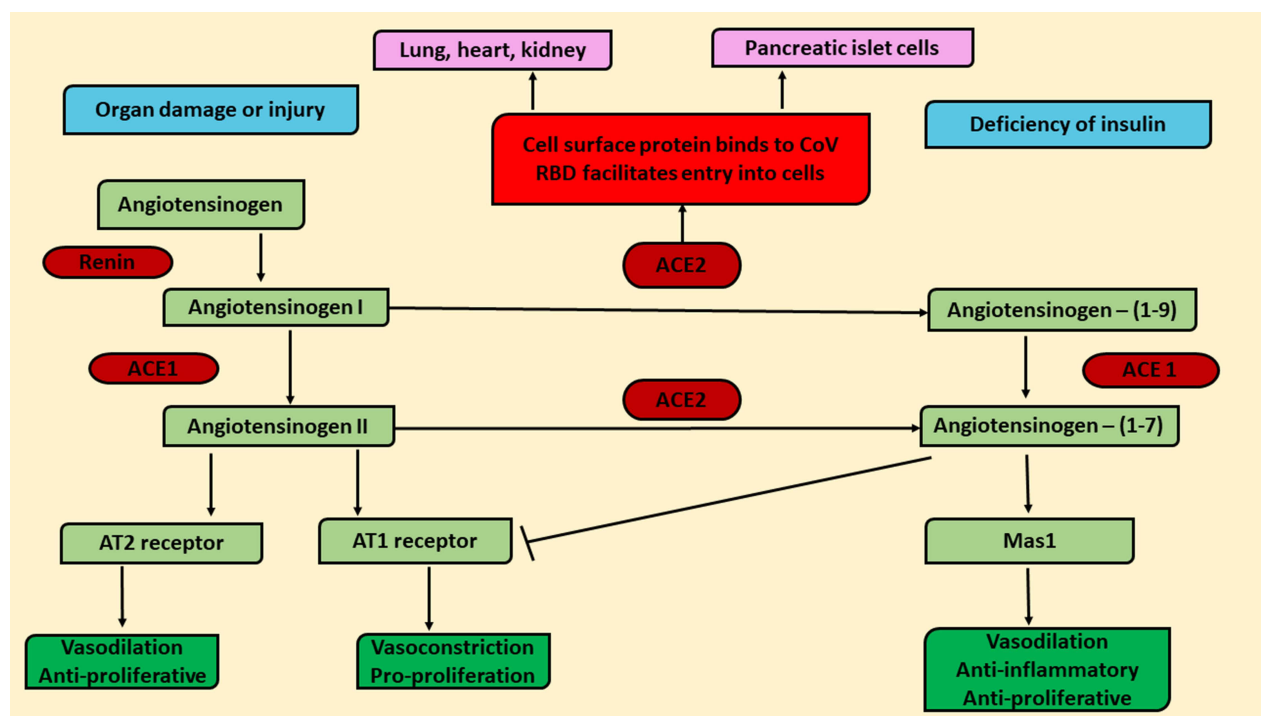

Figure 3 ACE2 role in COVID-19 pathogenesis. ACE2 transforms angiotensinogen I into angiotensinogen (I-9) and angiotensinogen II into angiotensinogen (I-7). ACE2 poses as a mediator for COVID-19COVID-19 entry into cells and is expressed in the pancreas, lungs, heart and kidneys. Angiotensinogen-I level increases due to ACEI use which upregulate the expression of the ACE2 gene. It causes overload entry of virus into cells, which leads to deficiency of insulin and organ damage or injury and contributes to high blood-glucose levels (hyperglycemia). After upregulation, ACE2 converts angiotensinogen II into angiotensinogen (I-7) and causes anti-inflammatory and antiproliferative effects by acting on Mas I receptors and also inhibit the AT, receptor to trigger vasoconstriction. Coronavirus infection downregulates the expression of ACE2 and reduces levelsand anti-inflammatory effects ofangiotensinogen (I-7), and organs become more vulnerable to infection.

Note: Data from Katulanda et al. $^{5}$

Abbreviations: RBD, receptor-binding domain; AT, angiotensin; CoV, coronavirus. 
levels, which leads to increased anti-inflammatory effects. However, COVID-19 infection downregulates the expression of ACE2 and reduces the level of angiotensinogen (17), which decreases the anti-inflammatory effects of angiotensinogen (1-7), and thus organs become more vulnerable to infection. ${ }^{113}$

\section{India's Situation During the COVID- 19 Pandemic}

There are many people currently living with DM in India. Around 18 million diabetics aged $\geq 65$ years are specifically susceptible to mortality because of COVID-19 pandemic. $^{120}$ This huge number is a major challenge in the assessment, management, and prevention of COVID-

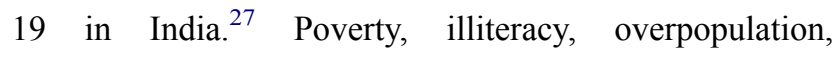
a distressed health-care system, and unplanned towns are the main obstacles in the fight against COVID-19 in India. $^{121}$ During lockdown, diabetics have raised their carbohydrate intake and also reduced physical exercise, which results in gain in body-weight gain and destabilization of blood-glucose levels in the body. ${ }^{122}$ A study examined the link between the period of lockdown in India and loss of glycemic control and subsequent complications. The projected increase in $\mathrm{HbA}_{1 \mathrm{c}}$ from base-line was $2.26 \%$ after 30 days of lockdown and $3.68 \%$ after 45 days of lockdown. The projected increase in complication rate was $2.9 \%$ for peripheral neuropathy, $2.8 \%$ for diabetic retinopathy, $0.5 \%$ for stroke, $0.9 \%$ for heart attacks, and $14.2 \%$ and $9.3 \%$ for proteinuria and microalbuminuria, respectively. ${ }^{123}$ This represents an increase in the number of people with DM and its complications. Pal et al reported that $72 \%$ of all T1DM patients complained of high blood glucose based on self-monitored bloodglucose records during the nationwide lockdowns in India. $^{124}$

Trained immunity provided by bacillus CalmetteGuérin (BCG) vaccination may offer some protection from the deleterious effects of COVID-19. ${ }^{125}$ In fact, lower mortality and disease burden were found in the primary weeks of the COVID-19 pandemic among countries that had a universal BCG-vaccination policy. ${ }^{126}$ However, several variations from this general finding have also been found. For instance, in Israel a study reported that people born after or during the universal BCG-vaccination policy did not exhibit any deviation in mortality or infection rate for COVID-19, though the study was limited to younger age-groups. ${ }^{127}$ Similarly, Brazil also had a universal BCG-vaccination policy for a long time, but also witnessed a rise in mortality and COVID-19 infection. ${ }^{128}$ Iran began universal vaccination in 1984, but did not exhibit the same protection from high mortality as seen in nations like India, which started universal BCG vaccination much earlier. ${ }^{129,130}$ As such, BCG vaccination may provide ethnicity-specific protection against viral microbes among South Asian populations, though the role of other factors needs to be examined.

\section{Management of Diabetes and Associated Complications in COVID-I 9 Infection}

COVID-19 with comorbidities leads to a fierce circle of high mortality and vast morbidity in infected patients. SARS-Co V2 exposure among people with comorbidities like CVD (reduced immunity and function of heart), DM (high expression of ACE2 and lung inflammation) are detrimental to the heart, liver, kidneys and lungs. These complications result in adverse impacts on the patient due to ARBs, shock, multiorgan failure, renal and heart failure, and ultimately death. ${ }^{131}$ The US National Institutes of Health (and the World Health Organization have released suggestions on the basis of expert advice and clinical evidence for optimum care of COVID-19 patients. $^{132}$ ThoughCOVID-19 patients mostly develop minor symptoms, around $20 \%$ require hospital care, $5 \%-$ $8 \%$ develop serious diseases and require critical care and ICU admission. ${ }^{37}$ Variation in ICU-admission rates in different nations depends on admission requirements and clinical practice in the particular region. Furthermore, the rate of ICU admission is also influenced by factors like comorbidity and age. Disorders like CVD, hypertension, DM, asthma, and malignancy have been found to be key risk factors of serious conditions in COVID-19 patients and increased mortality rate. As such, special attention should be paid to these patients. A pilot study observed that continuous glucose monitoring is needed even in non-critically ill diabetic patients with COVID-19 infection. ${ }^{133}$ Many COVID-19 patients die due to preexistent comorbidity, and thus correct assessment is needed at the time of admission to hospital. ${ }^{134}$ It is important to segregate COVID-19 patients with and without comorbidities into two distinct groups, and separate recommendations must be considered for these patients. ${ }^{105}$ People with comorbidities must adhere strictly to personal care routines, especially physical/social distancing and handwashing. ${ }^{135}$ Diabetic patients must increase their metabolic control as required, as it is a primary preventive step of 
COVID-19 infection. ${ }^{7}$ Influenza vaccination decreasespneumonia risk by $43 \%-55 \%$ among people with DM, and can be applied to distinguish symptoms of COVID-19 and influenza. ${ }^{136}$ Because of reduced immunity among patients with comorbidity, it is recommended that if a patient is experiencing minor symptoms that can be regulated at home, they should live inisolation. Additionally, physician consultations must be augmented for managing COVID-19 infection in patients with comorbidities. ${ }^{134}$ Sardu et al reported that during hospitalization, optimal glycemic control was linked to reduced risk of serious conditions and death in COVID-19 patients. They found that during hospitalization, D-dimer and IL6 levels were substantially higher in hyperglycemic patients than normoglycemic patients $(P<0.001) .{ }^{137}$ In T2DM patients, altered glucose homeostasis and insulin resistance cause interstitial lung disease and alveolar capillary microangiopathy via conditions like overinflammation. ${ }^{138}$ This suggests that COVID-19 patients with hyperglycemia are at higher risk of disease severity during hospitalization. Overactivation of innate immunity might be a poor outcome of COVID-19 infection in hyperglycemic patients, including those treated with tocilizumab, which is an IL6 inhibitor. ${ }^{139}$ Despite complete treatment with antivirals, oxygen therapy, and hydroxychloroquine, hyperglycemic patients with COVID-19 infection have poorer prognosis. ${ }^{140}$ These data suggest that early management of glycemia may be a potential therapeutic method to reduce poor outcomes among hospitalized hyperglycemic COVID19 patients with/without prior diagnosis of DM. ${ }^{141}$
Mostly, T2DM patients have other elements of metabolic disorders like dyslipidemia and hypertension. As such, continuous treatment is suitable for lowering lipids and hypertension in people with T2DM. Use of ARBs and ACEIs in treatment may enhance ACE2 expression, which facilitates virus entry into host cells (Figure 4). ${ }^{142}$ SARS-CoV2 may damage ACE2- and Mas1-receptor pathways and increase harmful AT2 action, as they can provide a safeguard against lung injury after COVID-19 infection. A recent study reported that ACEI and ARB prescriptions benefited COVID-19 patients in terms of reducing mortality and hospital stay. $^{143,144}$

Studies from the European Society of Cardiology, American College of Cardiology, American Heart Association, and Heart Failure Society of America have recommended that T2DM patients continue with hypertension treatment, which should include ARBs and ACEIs. ${ }^{7,145}$ Drugs, particularly statin, can fix the reduced ACE2 caused by high levels of lipids, such as low-density lipoprotein. ${ }^{146}$ Anti-inflammatory effects of statins contributed into upregulation of ACE2. Table 2 shows pharmacotherapies used during COVID-19 infection for DM and associated complications. ${ }^{5}$ Due to the close association between CVD and DM, the researchers recommended the management of concentration of lipids in COVID-19 patients. People who have undergone kidney, islet, or pancreas transplantation and those on immunosuppressive treatment are at high risk of COVID-19 infection. ${ }^{\text {? }}$

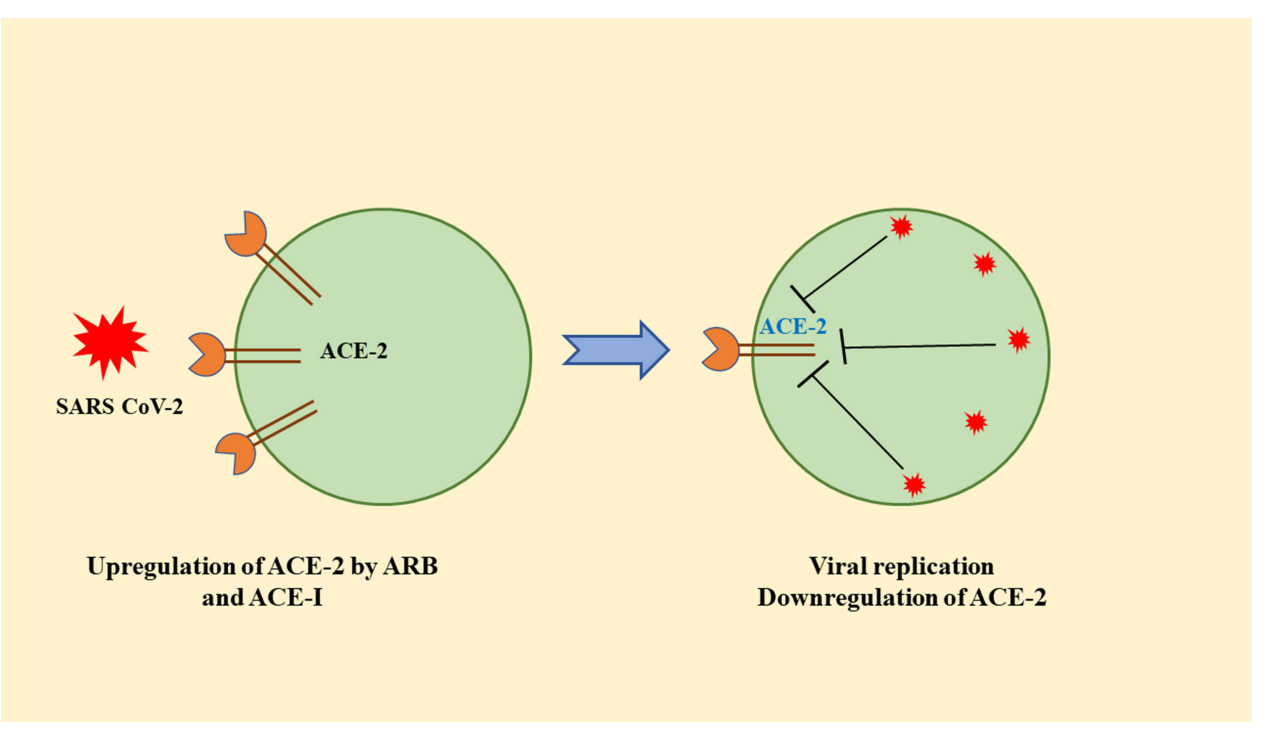

Figure 4 Interactions among SARS-CoV2 and pneumocytes. SARS-CoV2 enters cells through ACE2. ACE2 gets upregulated by ARB and ACEl. After entering host cells, the virus replicates and downregulates ACE2. This causes a decrease in angiotensin II and results in more aldosterone secretion and renal wasting of potassium.

Note: Data from Pal and Bhansali. ${ }^{163}$

Abbreviation: $A R B$, angiotensin receptor blocker. 
Table 2 Pharmacotherapies used during COVID-19 infection for DM and associated complications

\begin{tabular}{|l|l|}
\hline Considerations for use & \\
\hline Statins & Elevated myositis and transaminitis risk \\
Sulfonylureas & Risk of low blood-glucose level in cases of oral ingestion or in association with chloroquine/ hydroxychloroquine \\
Aspirin & CVD risk higher with COVID-19 infection \\
DPP4 inhibitors & Risk of low blood-glucose level is low, may use for several renal dysfunction \\
ACEI/ARBs & Risk of increased infection susceptibility and benefited in inflammatory injury \\
SGLT2 inhibitors & Elevated risk of euglycemic DM ketoacidosis and dehydration \\
Insulin & Regular monitoring is required \\
GLPIRAs & Aspiration risk and gastrointestinal side effects \\
Pioglitazone & Edema and fluid-retention risk, contraindicated during hemodynamic instability \\
Metformin & Lactic acidosis risk in conditions of hypoxia and acute infection \\
\hline
\end{tabular}

Note: Data from Katulanda et al. ${ }^{5}$

Data show that most T2DM patients are obese or overweight. BMI is a vital factor of oxygenation, lung volume, and respiratory mechanics at the time of automated ventilation in the body, particularly in a horizontal posture. Therefore, obese diabetic patients can be at higher risk of ventilation failure and problems at the time of automated ventilation. ${ }^{147}$ India has developed several national strategies and policies, such as the National Cancer Control Programme, National Trauma Care Programme and National Programme for Prevention and Control of Diabetes, Cardiovascular Disease, and Stroke, to carefully tackle the chronic disorder burden. ${ }^{148}$ SARS-CoV2 may cause long-term metabolic disorders in infected people. Similar results were observed in individuals infected with the SARS virus. ${ }^{149}$ There is a need for regular and constant cardiometabolic examination of people who have survived severe and critical SARS-CoV2 infections. ${ }^{7}$ COVID-19 is highly prevalent among health-care professionals with DM, who administer care to COVID-19 patients. Therefore, wherever possible, these workers must not work around sick people or they should use highlevel safety protocols. ${ }^{7,150}$ Dorjee et al suggested that appropriate management of modifiable risk factors like DM and hypertension may decrease mortality and morbidity due to COVID-19. ${ }^{70}$

\section{Recommended Steps for Good Health in Diabetic Individuals During the COVID-19 Pandemic}

People with DM must exercise regularly. Exercises like stationary running, cycling, resistance training, and treadmill are helpful, and everyone can easily follow this exercise routine in India. (a) Diabetic people should maintain consistency in their regular meals. They must eat healthily, with a balanced quantity of fibers and proteins. A limited amount of fat in food is vital to control blood-glucose levels.

(b) It is important to regularly take prescribed medicines or antidiabetic drugs and insulin on time.

(c) Patients should keep their feet clean to prevent problems linked to the feet.

(d) Old people should know the ambulance number (102) for emergency situations.

(e) Diabetic people should visit hospital immediately in emergency conditions, such as chest pain, altered senses, shortness of breath, drowsiness, weakness in the limbs, and vomiting. 8,151

\section{Conclusion}

SARS-CoV2 is extremely infectious and transmitted via respiratory droplets from infected persons. Severe cases of COVID-19 have been observed in people with comorbidities, particularly CVD, hypertension, and DM. An increasing number of studies have shown DM to be a vital risk factor affecting the severity of various other kinds of infection. Dysregulated immunoresponse found in diabetic patients plays an important role in exacerbating severity. DM is among the comorbidities linked to mortality and morbidity due to COVID-19. Chronic conditions like obesity, CVD, and hypertension together with changed expression of ACE2, dysregulated immunoresponse, and endothelial dysfunction may put diabetic patients at greater risk of COVID-19 infection. The awareness and opinions of people are likely to impact the great amount of protection methods and eventually affect the results of clinical research. Therefore, it is important to study specific characteristics of COVID- 
19 in diabetic people and treat comorbidities along with COVID-19 infection, mainly among old individuals who are already suffering from serious and critical infections.

\section{Acknowledgments}

We thank Jamia Millia Islamia for access to journals and the Indian Council of Medical Research, New Delhi, India.

Dr. Mirza Masroor Ali Beg advises he is now affiliated with the Faculty of Medicine, Ala-Too International University, Bishkek, Kyrgyzstan and the Centre for Promotion of Medical Research, Ala-Too International University, Bishkek, Kyrgyzstan.

\section{Author Contributions}

All authors made a significant contribution to the work reported, whether in the conception, study design, execution, acquisition of data, analysis, interpretation, or all these areas, took part in drafting, revising, or critically reviewing the article, gave final approval to the version to be published, have agreed on the journal to which the article has been submitted, and agree to be accountable for all aspects of the work.

\section{Funding}

No source of funding.

\section{Disclosure}

The authors declare that they have no conflicts of interest associated with this work.

\section{References}

1. Gorbalenya AE, Baker SC, Baric R, et al. Severe acute respiratory syndrome-related coronavirus: the species and its viruses - a statement of the Coronavirus Study Group. 2020. doi: 10.13039/501100001659.

2. Muniyappa R, Gubbi S. COVID-19 pandemic, coronaviruses, and diabetes mellitus. Am J Physiol Endocrinol Metab. 2020;318(5): E736-E741. doi:10.1152/ajpendo.00124.2020

3. Chang D, Xu H, Rebaza A, Sharma L, Cruz CSD. Protecting health-care workers from subclinical coronavirus infection. Lancet Respir Med. 2020;8(3):e13. doi:10.1016/S2213-2600(20)30066-7

4. Lin L, Lu L, Cao W, Li T. Hypothesis for potential pathogenesis of SARS-CoV-2 infection-a review of immune changes in patients with viral pneumonia. Emerg Microb Infect. 2020;9(1):727-732. doi:10.1080/22221751.2020.1746199

5. Katulanda P, Dissanayake HA, Ranathunga I, et al. Prevention and management of COVID-19 among patients with diabetes: an appraisal of the literature. Diabetologia. 2020;63(8):1440-1452. doi:10.1007/ s00125-020-05164-x

6. Whitworth J. COVID-19: a fast evolving pandemic. Trans $R$ Soc Trop Med Hyg. 2020;114(4):241-248. doi:10.1093/trstmh/traa025

7. Bornstein SR, Rubino F, Khunti K, et al. Practical recommendations for the management of diabetes in patients with COVID-19. Lancet Diabetes Endocrinol. 2020;8(6):546-550. doi:10.1016/S2213$8587(20) 30152-2$
8. Singh AK, Gupta R, Ghosh A, Misra A. Diabetes in COVID-19: prevalence, pathophysiology, prognosis and practical considerations. Diabetes Metab Syndr. 2020;14(4):303-310. doi:10.1016/j.dsx.2020.04.004

9. Fung M, Babik JM. COVID-19 in immunocompromised hosts: what we know so far. Clin Infect Dis. 2020;ciaa863. doi:10.1093/ cid/ciaa863

10. Burki TK. Cancer guidelines during the COVID-19 pandemic. Lancet Oncol. 2020;21(5):629-630. doi:10.1016/S1470-2045(20) 30217-5

11. Prabhu S, Poongulali S, Kumarasamy N. Impact of COVID-19 on people living with HIV: a review. J Virus Erad. 2020;6 (4):100019. doi:10.1016/j.jve.2020.100019

12. Sahu KK, Mishra AK, Lal A. A twin challenge to handle: COVID-19 with pregnancy. $J$ Med Virol. 2020;92 (10):1718-1720. doi:10.1002/jmv.25784

13. WHO coronavirus disease (COVID-19). Available from: https:// covid19.who.int. Accessed June 25, 2021.

14. India-World Health Organization. Coronavirus disease (COVID-19). Available from: https://www.who.int/india/emergen cies/coronavirus-disease-(covid-19). Accessed June 25, 2021.

15. Saeedi P, Petersohn I, Salpea P, et al. Global and regional diabetes prevalence estimates for 2019 and projections for 2030 and 2045 results from the International Diabetes Federation Diabetes Atlas, 9th edition. Diabetes Res Clin Pract. 2019;157:107843. doi:10.1016/j.diabres.2019.107843

16. IDF Diabetes Atlas. IDF diabetes atlas, 9th edn. Brussels and Belgium; 2019. Available from: https://www.diabetesatlas.org. Accessed June 25, 2021.

17. Goyal Y, Verma A, Bhatt D, Rahmani A, Dev K. Diabetes: perspective and challenges in modern era. Gene Rep. 2020;20:100759. doi:10.1016/j.genrep.2020.100759

18. Carey IM, Critchley JA, DeWilde S, Harris T, Hosking FJ, Cook DG. Risk of infection in type 1 and type 2 diabetes compared with the general population: a matched cohort study. Diabetes Care. 2018;41(3):513-521. doi:10.2337/dc17-2131

19. Verma AK, Beg MMA, Khan NA, Goyal Y, Dev K, Joshi PC. CDKAL1 ((rs10946398)) and TCF7L2 ((rs7903146)) gene polymorphisms and their association with risk of type-2 diabetes mellitus in population of Uttarakhand, India. Meta Gene. 2020;26:100767. doi:10.1016/j.mgene.2020.100767

20. Peleg AY, Weerarathna T, McCarthy JS, Davis TME. Common infections in diabetes: pathogenesis, management and relationship to glycaemic control. Diabetes Metab Res Rev. 2007;23(1):3-13. doi:10.1002/dmrr.682

21. Castellanos MR, Szerszen A, Saifan C, et al. Fasting hyperglycemia upon hospital admission is associated with higher pneumonia complication rates among the elderly. Int Arch Med. 2010;3:16. doi:10.1186/1755-7682-3-16

22. Kornum JB, Thomsen RW, Riis A, Lervang -H-H, Schønheyder HC, Sørensen HT. Type 2 diabetes and pneumonia outcomes: a population-based cohort study. Diabetes Care. 2007;30(9):2251-2257. doi:10.2337/dc06-2417

23. Yang JK, Feng Y, Yuan MY, et al. Plasma glucose levels and diabetes are independent predictors for mortality and morbidity in patients with SARS. Diabetic Med. 2006;23(6):623-628. doi:10.1111/j.1464-5491.2006.01861.x

24. Yang YM, Hsu CY, Lai CC, et al. Impact of comorbidity on fatality rate of patients with Middle East respiratory syndrome. Sci Rep. 2017;7(1):1-9. doi:10.1038/s41598-017-10402-1

25. Garbati MA, Fagbo SF, Fang VJ, et al. A comparative study of clinical presentation and risk factors for adverse outcome in patients hospitalised with acute respiratory disease due to MERS coronavirus or other causes. PLoS One. 2016;11(11): e0165978. doi:10.1371/journal.pone.0165978 
26. Allard R, Leclerc P, Tremblay C, Tannenbaum T-N. Diabetes and the severity of pandemic influenza A (H1N1) infection. Diabetes Care. 2010;33(7):1491-1493. doi:10.2337/dc09-2215

27. Guan W, Ni Z-Y, Hu Y, et al. Clinical characteristics of coronavirus disease 2019 in China. $N$ Engl $J$ Med. 2020;382 (18):1708-1720. doi:10.1056/NEJMoa2002032

28. Lauer SA, Grantz KH, Bi Q, et al. The incubation period of coronavirus disease 2019 (COVID-19) from publicly reported confirmed cases: estimation and application. Ann Intern Med. 2020;172(9):577-582. doi:10.7326/M20-0504

29. Hussain A, Bhowmik B, Do Vale Moreira NC. COVID-19 and diabetes: knowledge in progress. Diabetes Res Clin Pract. 2020;162:108142. doi:10.1016/j.diabres.2020.108142

30. Jalava K. First respiratory transmitted food borne outbreak? Int J Hyg Environ Health. 2020;226:113490. doi:10.1016/j. ijheh.2020.113490

31. Guo YR, Cao QD, Hong ZS, et al. The origin, transmission and clinical therapies on coronavirus disease 2019 (COVID-19) outbreak - an update on the status. Mil Med Res. 2020;7(1):11. doi:10.1186/s40779-020-00240-0

32. Adhikari SP, Meng S, Wu YJ, et al. Epidemiology, causes, clinical manifestation and diagnosis, prevention and control of coronavirus disease (COVID-19) during the early outbreak period: a scoping review. Infect Dis Poverty. 2020;9(1):29. doi:10.1186/ s40249-020-00646-x

33. van Doremalen N, Bushmaker T, Morris DH, et al. Aerosol and surface stability of SARS-CoV-2 as compared with SARS-CoV-1. NEngl JMed. 2020;382(16):1564-1567. doi:10.1056/NEJMc2004973

34. Shi Y, Wang Y, Shao C, et al. COVID-19 infection: the perspectives on immune responses. Cell Death Differ. 2020;27 (5):1451-1454. doi:10.1038/s41418-020-0530-3

35. Wang $\mathrm{D}, \mathrm{Hu} \mathrm{B}, \mathrm{Hu} \mathrm{C}$, et al. Clinical characteristics of 138 hospitalized patients with 2019 novel coronavirus-infected pneumonia in Wuhan, China. JAMA. 2020;323(11):1061-1069. doi:10.1001/jama.2020.1585

36. Li B, Yang J, Zhao F, et al. Prevalence and impact of cardiovascular metabolic diseases on COVID-19 in China. Clin Res Cardiol. 2020;109(5):531-538. doi:10.1007/s00392-020-01626-9

37. Wu Z, McGoogan JM. Characteristics of and important lessons from the coronavirus disease 2019 (COVID-19) outbreak in China: summary of a report of 72314 cases from the Chinese center for disease control and prevention. JAMA. 2020;323 (13):1239-1242. doi:10.1001/jama.2020.2648

38. Zhou F, Yu T, Du R, et al. Clinical course and risk factors for mortality of adult inpatients with COVID-19 in Wuhan, China: a retrospective cohort study. Lancet. 2020;395 (10229):1054-1062. doi:10.1016/S0140-6736(20)30566-3

39. Erener S. Diabetes, infection risk and COVID-19. Mol Metab. 2020;39:101044. doi:10.1016/j.molmet.2020.101044

40. Zou L, Ruan F, Huang M, et al. SARS-CoV-2 viral load in upper respiratory specimens of infected patients. $N$ Engl $J$ Med. 2020;382(12):1177-1179. doi:10.1056/NEJMc2001737

41. Liu Y, Yan LM, Wan L, et al. Viral dynamics in mild and severe cases of COVID-19. Lancet Infect Dis. 2020;20(6):656-657. doi:10.1016/S1473-3099(20)30232-2

42. Li Z, Yi Y, Luo X, et al. Development and clinical application of a rapid IgM-IgG combined antibody test for SARS-CoV-2 infection diagnosis. J Med Virol. 2020. doi:10.1002/jmv.25727

43. Chu DKW, Pan Y, Cheng SMS, et al. Molecular diagnosis of a novel coronavirus $(2019-\mathrm{nCoV})$ causing an outbreak of pneumonia. Clin Chem. 2020;66(4):549-555. doi:10.1093/clinchem/hvaa029

44. Corman VM, Landt O, Kaiser M, et al. Detection of 2019 novel coronavirus (2019-nCoV) by real-time RT-PCR. Euro Surveill. 2020;25(3). doi:10.2807/1560-7917.ES.2020.25.3.2000045
45. Chan JFW, Yip CCY, To KKW, et al. Improved molecular diagnosis of COVID-19 by the novel, highly sensitive and specific COVID-19-RdRp/Hel real-time reverse transcription-PCR assay validated in vitro and with clinical specimens. J Clin Microbiol. 2020;58(5). doi:10.1128/JCM.00310-20

46. Craw P, Balachandran W. Isothermal nucleic acid amplification technologies for point-of-care diagnostics: a critical review. $L a b$ Chip. 2012;12(14):2469-2486. doi:10.1039/c2lc40100b

47. Vincent M, Xu Y, Kong H. Helicase-dependent isothermal DNA amplification. EMBO Rep. 2004;5(8):795-800. doi:10.1038/sj. embor.7400200

48. Compton J. Nucleic acid sequence-based amplification. Nature. 1991;350(6313):91-92. doi:10.1038/350091a0

49. Walker GT, Fraiser MS, Schram JL, Little MC, Nadeau JG, Malinowski DP. Strand displacement amplification--an isothermal, in vitro DNA amplification technique. Nucleic Acids Res. 1992;20(7):1691-1696. doi:10.1093/nar/20.7.1691

50. Li J, Macdonald J, von Stetten F. Review: a comprehensive summary of a decade development of the recombinase polymerase amplification. Analyst. 2018;144(1):31-67. doi:10.1039/ C8AN01621F

51. Notomi T, Okayama H, Masubuchi H, et al. Loop-mediated isothermal amplification of DNA. Nucleic Acids Res. 2000;28(12): E63. doi:10.1093/nar/28.12.e63

52. Lamb LE, Bartolone SN, Ward E, Chancellor MB, Kalendar R. Rapid detection of novel coronavirus/severe acute respiratory syndrome coronavirus 2 (SARS-CoV-2) by reverse transcription-loop-mediated isothermal amplification. PLoS One. 2020;15(6):e0234682. doi:10.1371/journal.pone.0234682

53. Udugama B, Kadhiresan $\mathrm{P}$, Kozlowski HN, et al. Diagnosing COVID-19: the disease and tools for detection. ACS Nano. 2020;14(4):3822-3835. doi:10.1021/acsnano.0c02624

54. Mori Y, Nagamine K, Tomita N, Notomi T. Detection of loop-mediated isothermal amplification reaction by turbidity derived from magnesium pyrophosphate formation. Biochem Biophys Res Commun. 2001;289(1):150-154. doi:10.1006/ bbrc.2001.5921

55. Kim J, Biondi MJ, Feld JJ, Chan WCW. Clinical validation of quantum dot barcode diagnostic technology. ACS Nano. 2016;10 (4):4742-4753. doi:10.1021/acsnano.6b01254

56. Elnifro EM, Ashshi AM, Cooper RJ, Klapper PE. Multiplex PCR: optimization and application in diagnostic virology. Clin Microbiol Rev. 2000;13(4):559-570. doi:10.1128/cmr.13.4.559-570.2000

57. Dunbar SA. Applications of Luminex xMAP technology for rapid, high-throughput multiplexed nucleic acid detection. Clin Chim Acta. 2006;363(1-2):71-82. doi:10.1016/j.ccen.20 05.06.023

58. Chen Y, Chan K-H, Hong C, et al. A highly specific rapid antigen detection assay for on-site diagnosis of MERS. $J$ Infect. 2016;73 (1):82-84. doi:10.1016/j.jinf.2016.04.014

59. Lau SKP, Woo PCY, Wong BHL, et al. Detection of severe acute respiratory syndrome (SARS) coronavirus nucleocapsid protein in sars patients by enzyme-linked immunosorbent assay. $J$ Clin Microbiol. 2004;42(7):2884-2889. doi:10.1128/JCM.42.7.28842889.2004

60. Sastre P, Dijkman R, Camunas A, et al. Differentiation between human coronaviruses NL63 and 229E using a novel double-antibody sandwich enzyme-linked immunosorbent assay based on specific monoclonal antibodies. Clin Vaccine Immunol. 2011;18(1):113-118. doi:10.1128/CVI.00355-10

61. Liu IJ, Chen PJ, Yeh SH, et al. Immunofluorescence assay for detection of the nucleocapsid antigen of the severe acute respiratory syndrome (SARS)-associated coronavirus in cells derived from throat wash samples of patients with SARS. $J$ Clin Microbiol. 2005;43(5):2444-2448. doi:10.1128/JCM.43.5.24442448.2005 
62. Guo L, Ren L, Yang S, et al. Profiling early humoral response to diagnose novel coronavirus disease (COVID-19). Clin Infect Dis. 2020;71(15):778-785. doi:10.1093/cid/ciaa310

63. Hijnen D, Marzano AV, Eyerich K, et al. Early release SARS-CoV-2 transmission from presymptomatic meeting attendee, Germany. Emerg Infect Dis J. 2020;26(8). doi:10.3201/ eid2608.201235

64. Shen C, Wang Z, Zhao F, et al. Treatment of 5 critically ill patients with COVID-19 with convalescent plasma. JAMA. 2020;323(16):1582-1589. doi:10.1001/jama.2020.4783

65. Walls AC, Tortorici MA, Frenz B, et al. Glycan shield and epitope masking of a coronavirus spike protein observed by cryo-electron microscopy. Nat Struct Mol Biol. 2016;23 (10):899-905. doi:10.1038/nsmb.3293

66. Leung DTM, Tam F, Ma C, et al. Antibody response of patients with severe acute respiratory syndrome (SARS) targets the viral nucleocapsid. J Infect Dis. 2004;190(2):379-386. doi:10.1086/ 422040

67. Jin Y, Wang M, Zuo Z, et al. Diagnostic value and dynamic variance of serum antibody in coronavirus disease 2019. Int J Infect Dis. 2020;94:49-52. doi:10.1016/j.ijid.2020.03.065

68. Li R, Tian X, Yu Y, Qiao S, Wang Z, Ma J. Development of a rapid immunochromatographic assay for detection of antibodies against porcine epidemic diarrhea virus. Pol J Vet Sci. 2018;21 (1):139-147. doi:10.24425/119032

69. Yang J, Zheng Y, Gou X, et al. Prevalence of comorbidities and its effects in patients infected with SARS-CoV-2: a systematic review and meta-analysis. Int $J$ Infect Dis. 2020;94:91-95. doi:10.1016/j.ijid.2020.03.017

70. Dorjee K, Kim H, Bonomo E, Dolma R, Bolignano D. Prevalence and predictors of death and severe disease in patients hospitalized due to COVID-19: a comprehensive systematic review and meta-analysis of 77 studies and 38,000 patients. PLoS One. 2020;15(12):e0243191. doi:10.1371/journal.pone.0243191

71. Alshebri MS, Alshouimi RA, Alhumidi HA, Alshaya AI. Neurological complications of SARS-CoV, MERS-CoV, and COVID-19. SN Compr Clin Med. 2020;2(11):2037-2047. doi:10.1007/s42399-020-00589-2

72. Sardu C, Gambardella J, Morelli MB, Wang X, Marfella R, Santulli G. Hypertension, thrombosis, kidney failure, and diabetes: is COVID-19 an endothelial disease? A comprehensive evaluation of clinical and basic evidence. J Clin Med. 2020;9 (5):1417. doi: $10.3390 / \mathrm{jcm} 9051417$

73. Sardu C, Marfella R, Maggi P, et al. Implications of AB0 blood group in hypertensive patients with covid-19. BMC Cardiovasc Disord. 2020;20(1):373. doi:10.1186/s12872-020-01658-Z

74. Lip GY. Hypertension and the prothrombotic state. J Hum Hypertens. 2000;14(10-11):687-690. doi:10.1038/sj.jhh.1001051

75. Sardu C, Maggi P, Messina V, et al. Could anti-hypertensive drug therapy affect the clinical prognosis of hypertensive patients with COVID-19 infection? Data from centers of Southern Italy. $J \mathrm{Am}$ Heart Assoc. 2020;9(17):e016948. doi:10.1161/JAHA.120.016948

76. Yaghi S, Ishida $\mathrm{K}$, Torres $\mathrm{J}$, et al. SARS-CoV-2 and stroke in a New York healthcare system. Stroke. 2020;51(7):2002-2011. doi:10.1161/STROKEAHA.120.030335

77. González-Pinto T, Luna-Rodríguez A, Moreno-Estébanez A, Agirre-Beitia G, Rodríguez-Antigüedad A, Ruiz-Lopez M. Emergency room neurology in times of COVID-19: malignant ischaemic stroke and SARS-CoV-2 infection. Eur J Neurol. 2020;27(9):e35-e36. doi:10.1111/ene.14286

78. Hughes C, Nichols T, Pike M, Subbe C, Elghenzai S. Cerebral venous sinus thrombosis as a presentation of COVID-19. Eur J Case Rep Intern Med. 2020;7(5):001691. doi:10.12890/2020_001691

79. Yang D, Xiao Y, Chen J, et al. COVID-19 and chronic renal disease: clinical characteristics and prognosis. QJM. 2020;113 (11):799-805. doi:10.1093/qjmed/hcaa258
80. Gupta N, Agrawal S, Ish P, et al. Clinical and epidemiologic profile of the initial COVID-19 patients at a tertiary care centre in India. Monaldi Arch Chest Dis. 2020;90(1). doi:10.4081/ monaldi.2020.1294

81. Onder G, Rezza G, Brusaferro S. Case-fatality rate and characteristics of patients dying in relation to COVID-19 in Italy. JAMA. 2020;323(18):1775-1776. doi:10.1001/jama.2020.4683

82. Huang C, Wang Y, Li X, et al. Clinical features of patients infected with 2019 novel coronavirus in Wuhan, China. Lancet. 2020;395(10223):497-506. doi:10.1016/S0140-6736(20)30183-5

83. Williams R, Karuranga S, Malanda B, et al. Global and regional estimates and projections of diabetes-related health expenditure: results from the International Diabetes Federation Diabetes Atlas, 9th edition. Diabetes Res Clin Pract. 2020;162:108072. doi:10.1016/j.diabres.2020.108072

84. McDonald HI, Nitsch D, Millett ERC, Sinclair A, Thomas SL. New estimates of the burden of acute community-acquired infections among older people with diabetes mellitus: a retrospective cohort study using linked electronic health records. Diabet Med. 2014;31(5):606-614. doi:10.1111/dme.12384

85. Li S, Wang J, Zhang B, Li X, Liu Y. Diabetes mellitus and cause-specific mortality: a population-based study. Diabetes Metab J. 2019;43(3):319-341. doi:10.4093/dmj.2018.0060

86. Schoen K, Horvat N, Guerreiro NFC, de Castro I, de Giassi KS. Spectrum of clinical and radiographic findings in patients with diagnosis of $\mathrm{H} 1 \mathrm{~N} 1$ and correlation with clinical severity. $B M C$ Infect Dis. 2019;19(1):964. doi:10.1186/s12879-019-4592-0

87. Banik GR, Alqahtani AS, Booy R, Rashid H. Risk factors for severity and mortality in patients with MERS-CoV: analysis of publicly available data from Saudi Arabia. Virol Sin. 2016;31 (1):81-84. doi:10.1007/s12250-015-3679-z

88. EpiCentro. Characteristics of COVID-19 patients dying in Italy. Available from: https://www.epicentro.iss.it/en/coronavirus/sarscov-2-analysis-of-deaths. Accessed July 03, 2020.

89. Chen Y, Yang D, Cheng B, et al. Clinical characteristics and outcomes of patients with diabetes and COVID-19 in association with glucose-lowering medication. Diabetes Care. 2020;43 (7):1399-1407. doi:10.2337/dc20-0660

90. Wang A, Zhao W, Xu Z, Gu J. Timely blood glucose management for the outbreak of 2019 novel coronavirus disease (COVID-19) is urgently needed. Diabetes Res Clin Pract. 2020;162:108118. doi:10.1016/j.diabres.2020.108118

91. Petrie JR, Guzik TJ, Touyz RM. Diabetes, hypertension, and cardiovascular disease: clinical insights and vascular mechanisms. Can J Cardiol. 2018;34(5):575-584. doi:10.1016/j. cjca.2017.12.005

92. Knapp S. Diabetes and infection: is there a link? - A mini-review. GER. 2013;59(2):99-104. doi:10.1159/000345107

93. Apicella M, Campopiano MC, Mantuano M, Mazoni L, Coppelli A, Prato SD. COVID-19 in people with diabetes: understanding the reasons for worse outcomes. Lancet Diabetes Endocrinol. 2020;8(9):782-792. doi:10.1016/S2213-8587(20) 30238-2

94. Raoufi M, Khalili S, Mansouri M, Mahdavi A, Khalili N. Wellcontrolled vs poorly-controlled diabetes in patients with COVID-19: are there any differences in outcomes and imaging findings? Diabetes Res Clin Pract. 2020;166:108286. doi:10.1016/j.diabres.2020.108286

95. Geerlings SE, Hoepelman AIM. Immune dysfunction in patients with diabetes mellitus (DM). FEMS Immunol Med Microbiol. 1999;26(3-4):259-265. doi:10.1111/j.1574-695X.1999.tb01397.x

96. Ilyas R, Wallis R, Soilleux EJ, et al. High glucose disrupts oligosaccharide recognition function via competitive inhibition: a potential mechanism for immune dysregulation in diabetes mellitus. Immunobiology. 2011;216(1):126-131. doi:10.1016/j. imbio.2010.06.002 
97. Reading PC, Allison J, Crouch EC, Anders EM. Increased susceptibility of diabetic mice to influenza virus infection: compromise of collectin-mediated host defense of the lung by glucose? $J$ Virol. 1998;72(8):6884-6887. doi:10.1128/JVI.72.8.6884-6887.1998

98. Lecube A, Pachón G, Petriz J, Hernández C, Simó R, Sesti G. Phagocytic activity is impaired in type 2 diabetes mellitus and increases after metabolic improvement. PLoS One. 2011;6(8): e23366. doi:10.1371/journal.pone.0023366

99. Huang J, Xiao Y, Zheng P, et al. Distinct neutrophil counts and functions in newly diagnosed type 1 diabetes, latent autoimmune diabetes in adults, and type 2 diabetes. Diabetes Metab Res Rev. 2019;35(1):e3064. doi:10.1002/dmrr.3064

100. Kratz M, Coats B, Hisert K, et al. Metabolic dysfunction drives a mechanistically distinct proinflammatory phenotype in adipose tissue macrophages. Cell Metab. 2014;20(4):614-625. doi:10.1016/j.cmet.2014.08.010

101. Kim JH, Park K, Lee SB, et al. Relationship between natural killer cell activity and glucose control in patients with type 2 diabetes and prediabetes. $J$ Diabetes Investig. 2019;10 (5):1223-1228. doi:10.1111/jdi.13002

102. Alexandraki KI, Piperi C, Ziakas PD, et al. Cytokine secretion in long-standing diabetes mellitus type 1 and 2: associations with low-grade systemic inflammation. J Clin Immunol. 2008;28 (4):314-321. doi:10.1007/s10875-007-9164-1

103. Menart-Houtermans B, Rütter R, Nowotny B, et al. Leukocyte profiles differ between type 1 and type 2 diabetes and are associated with metabolic phenotypes: results from the German diabetes study (GDS). Diabetes Care. 2014;37(8):2326-2333. doi:10.2337/dc14-0316

104. Chen IY, Moriyama M, Chang MF, Ichinohe T. Severe acute respiratory syndrome coronavirus viroporin $3 \mathrm{a}$ activates the NLRP3 inflammasome. Front Microbiol. 2019;10. doi:10.3389/ fmicb.2019.00050

105. Wang T, Du Z, Zhu F, et al. Comorbidities and multi-organ injuries in the treatment of COVID-19'. Lancet. 2020;395 (10228):e52. doi:10.1016/S0140-6736(20)30558-4

106. Monteil V, Kwon H, Prado P, et al. Inhibition of SARS-CoV-2 infections in engineered human tissues using clinical-grade soluble human ACE2. Cell. 2020;181(4):905-913.e7. doi:10.1016/j. cell.2020.04.004

107. Varga Z, Flammer AJ, Steiger P, et al. Endothelial cell infection and endotheliitis in COVID-19. Lancet. 2020;395 (10234):1417-1418. doi:10.1016/S0140-6736(20)30937-5

108. Avogaro A, Albiero M, Menegazzo L, de Kreutzenberg S, Fadini GP. Endothelial dysfunction in Diabetes: the role of reparatory mechanisms. Diabetes Care. 2011;34(Supplement_2): S285-S290. doi:10.2337/dc11-s239

109. Letko M, Marzi A, Munster V. Functional assessment of cell entry and receptor usage for SARS-CoV-2 and other lineage B betacoronaviruses. Nat Microbiol. 2020;5(4):562-569. doi:10.1038/s41564-020-0688-y

110. Iwai $\mathrm{M}$, Horiuchi $\mathrm{M}$. Devil and angel in the renin-angiotensin system: ACE-angiotensin II-AT 1 receptor axis vs. ACE2-angiotensin-(1-7)-Mas receptor axis. Hypertens Res. 2009;32 (7):533-536. doi:10.1038/hr.2009.74

111. Wu J, Deng W, Li S, Yang X. Advances in research on ACE2 as a receptor for 2019-nCoV. Cell Mol Life Sci. 2020;1-14. doi:10.1007/s00018-020-03611-x

112. Serfozo P, Wysocki J, Gulua G, et al. Ang II (Angiotensin II) conversion to angiotensin-(1-7) in the circulation is POP (Prolyloligopeptidase)-dependent and ACE2 (Angiotensin-Converting Enzyme 2)-Independent. Hypertension. 2020;75(1):173-182. doi:10.1161/HYPERTENSIONAHA.1 19.14071
113. Vaduganathan $M$, Vardeny $\mathrm{O}$, Michel $\mathrm{T}$, McMurray JJV, Pfeffer MA, Solomon SD. Renin-angiotensin-aldosterone system inhibitors in patients with Covid-19. N Engl J Med. 2020;382 (17):1653-1659. doi:10.1056/NEJMsr2005760

114. Imai $\mathrm{Y}, \mathrm{Kuba} \mathrm{K}, \mathrm{Rao} \mathrm{S}$, et al. Angiotensin-converting enzyme 2 protects from severe acute lung failure. Nature. 2005;436 (7047):112-116. doi:10.1038/nature03712

115. Khan A, Benthin C, Zeno B, et al. A pilot clinical trial of recombinant human angiotensin-converting enzyme 2 in acute respiratory distress syndrome. Critical Care. 2017;21(1):234. doi:10.1186/s13054-017-1823-x

116. Gu J, Korteweg C. Pathology and pathogenesis of severe acute respiratory syndrome. Am J Pathol. 2007;170(4):1136-1147. doi:10.2353/ajpath.2007.061088

117. Yang JK, Lin SS, Ji XJ, Guo LM. Binding of SARS coronavirus to its receptor damages islets and causes acute diabetes. Acta Diabetol. 2010;47(3):193-199. doi:10.1007/s00592-009-0109-4

118. Furuhashi M, Moniwa N, Mita $\mathrm{T}$, et al. Urinary angiotensin-converting enzyme 2 in hypertensive patients may be increased by olmesartan, an angiotensin II receptor blocker. Am J Hypertens. 2015;28(1):15-21. doi:10.1093/ajh/hpu086

119. Wan Y, Shang J, Graham R, Baric RS, Li F, Gallagher T. Receptor recognition by the novel coronavirus from Wuhan: an analysis based on decade-long structural studies of SARS coronavirus. J Virol. 2020;94(7). doi:10.1128/JVI.00127-20

120. Caballero AE, Ceriello A, Misra A, et al. COVID-19 in people living with diabetes: an international consensus. $J$ Diabetes Complications. 2020;34(9):107671. doi:10.1016/j.jdiacomp.20 20.107671

121. Sahu KK, Mishra AK, Lal A, Sahu SA. India fights back: COVID-19 pandemic. Heart Lung. 2020;49(5):446-448. doi:10.1016/j.hrtlng.2020.04.014

122. Ghosh A, Arora B, Gupta R, Anoop S, Misra A. Effects of nationwide lockdown during COVID-19 epidemic on lifestyle and other medical issues of patients with type 2 diabetes in north India. Diabetes Metab Syndr. 2020;14(5):917-920. doi:10.1016/j.dsx.2020.05.044

123. Ghosal S, Sinha B, Majumder M, Misra A. Estimation of effects of nationwide lockdown for containing coronavirus infection on worsening of glycosylated haemoglobin and increase in diabetes-related complications: a simulation model using multivariate regression analysis. Diabetes Metab Syndr. 2020;14 (4):319-323. doi:10.1016/j.dsx.2020.03.014

124. Pal R, Yadav U, Verma A, Bhadada SK. Awareness regarding COVID-19 and problems being faced by young adults with type 1 diabetes mellitus amid nationwide lockdown in India: a qualitative interview study. Prim Care Diabetes. 2021;15 (1):10-15. doi:10.1016/j.pcd.2020.07.001

125. Escobar LE, Molina-Cruz A, Barillas-Mury C. BCG vaccine protection from severe coronavirus disease 2019 (COVID-19). PNAS. 2020;117(30):17720-17726. doi:10.1073/pnas.2008410117

126. Miller A, Reandelar MJ, Fasciglione K, Roumenova V, Li Y, Otazu GH. Correlation between universal BCG vaccination policy and reduced mortality for COVID-19. medRxiv. 2020. doi:10.1101/2020.03.24.20042937

127. Hamiel U, Kozer E, Youngster I. SARS-CoV-2 rates in BCG-vaccinated and unvaccinated young adults. JAMA. 2020;323(22):2340-2341. doi:10.1001/jama.2020.8189

128. Sala G, Chakraborti R, Ota A, Miyakawa T. Association of BCG vaccination policy and tuberculosis burden with incidence and mortality of COVID-19'. medRxiv. 2020. doi:10.1101/ 2020.03.30.20048165

129. Lahariya C. A brief history of vaccines \& vaccination in India. Indian J Med Res. 2014;139(4):491-511. 
130. Gupta R, Misra A. COVID19 in South Asians/Asian Indians: heterogeneity of data and implications for pathophysiology and research. Diabetes Res Clin Pract. 2020;165:108267. doi:10.1016/j.diabres.2020.108267

131. Zaim S, Chong JH, Sankaranarayanan V, Harky A. COVID-19 and multiorgan response. Curr Probl Cardiol. 2020;45 (8):100618. doi:10.1016/j.cpcardiol.2020.100618

132. World Health Organization. Clinical management of COVID-19: interim guidance, 27 May 2020. 2020. Available from: https:// apps.who.int/iris/handle/10665/332196. Accessed January 15, 2021.

133. Reutrakul S, Genco M, Salinas H, et al. Feasibility of inpatient continuous glucose monitoring during the COVID-19 pandemic: early experience. Diabetes Care. 2020;43(10):e137-e138. doi: $10.2337 / \mathrm{dc} 20-1503$

134. Ejaz H, Alsrhani A, Zafar A, et al. COVID-19 and comorbidities: deleterious impact on infected patients. $J$ Infect Public Health. 2020. doi:10.1016/j.jiph.2020.07.014

135. Riddle MC, Buse JB, Franks PW, et al. COVID-19 in people with diabetes: urgently needed lessons from early reports. Diabetes Care. 2020;43(7):1378-1381. doi:10.2337/dci20-0024

136. Patel A, Jernigan DB, Abdirizak F, et al. Initial public health response and interim clinical guidance for the 2019 novel coronavirus outbreak - United States, December 31, 2019February 4, 2020. MMWR Morb Mortal Wkly Rep. 2020;69 (5):140-146. doi:10.15585/mmwr.mm6905e1

137. Sardu C, D'Onofrio N, Balestrieri ML, et al. Outcomes in patients with hyperglycemia affected by COVID-19: can we do more on glycemic control? Diabetes Care. 2020;43(7):1408-1415. doi: $10.2337 / \mathrm{dc} 20-0723$

138. Sardu C, Gargiulo G, Esposito G, Paolisso G, Marfella R. Impact of diabetes mellitus on clinical outcomes in patients affected by Covid-19. Cardiovasc Diabetol. 2020;19(1):76. doi:10.1186/ s12933-020-01047-y

139. Marfella R, Paolisso P, Sardu C, et al. Negative impact of hyperglycaemia on tocilizumab therapy in Covid-19 patients. Diabetes Metab. 2020;46(5):403-405. doi:10.1016/j.diabet.2020.05.005

140. Sardu C, D'Onofrio N, Balestrieri ML, et al. Hyperglycaemia on admission to hospital and COVID-19. Diabetologia. 2020;63:2486-2487. doi:10.1007/s00125-020-05216-2

141. Shehav-Zaltzman G, Segal G, Konvalina N, Tirosh A. Remote glucose monitoring of hospitalized, quarantined patients with diabetes and COVID-19. Diabetes Care. 2020;43(7):e75-e76. doi: $10.2337 / \mathrm{dc} 20-0696$

142. Fang L, Karakiulakis G, Roth M. Are patients with hypertension and diabetes mellitus at increased risk for COVID-19 infection? Lancet Respir Med. 2020;8(4):e21. doi:10.1016/S2213-2600(20) 30116-8

143. Braude P, Carter B, Short R, et al. The influence of ACE inhibitors and ARBs on hospital length of stay and survival in people with COVID-19. IJC Heart Vasc. 2020;31:100660. doi:10.1016/j. ijcha.2020.100660

144. Hippisley-Cox J, Young D, Coupland C, et al. Risk of severe COVID-19 disease with ACE inhibitors and angiotensin receptor blockers: cohort study including 8.3 million people. Heart. 2020;106(19):1503-1511. doi:10.1136/heartjnl-2020-317393

145. Position statement of the ESC council on hypertension on ACE-inhibitors and angiotensin receptor blockers. Available from: https://www.escardio.org/Councils/Council-on-

Hypertension-(CHT)/News/position-statement-of-the-esc-council -on-hypertension-on-ace-inhibitors-and-ang, https://www.escar dio.org/Councils/Council-on-Hypertension-(CHT)/News/posi tion-statement-of-the-esc-council-on-hypertension-on-aceinhibitors-and-ang. Accessed July 03, 2020.
146. Shin YH, Min JJ, Lee J-H, et al. The effect of fluvastatin on cardiac fibrosis and angiotensin-converting enzyme-2 expression in glucose-controlled diabetic rat hearts. Heart Vessels. 2017;32 (5):618-627. doi:10.1007/s00380-016-0936-5

147. Andersen CJ, Murphy KE, Fernandez ML. Impact of obesity and metabolic syndrome on immunity. Adv Nutr. 2016;7(1):66-75. doi:10.3945/an.115.010207

148. Patel V, Chatterji S, Chisholm D, et al. Chronic diseases and injuries in India. Lancet. 2011;377(9763):413-428. doi:10.1016/ S0140-6736(10)61188-9

149. Luzi L, Radaelli MG. Influenza and obesity: its odd relationship and the lessons for COVID-19 pandemic. Acta Diabetol. 2020;1-6. doi:10.1007/s00592-020-01522-8

150. Wu Q, Zhou L, Sun X, et al. Altered lipid metabolism in recovered SARS patients twelve years after infection. Sci Rep. 2017;7 (1):1-12. doi:10.1038/s41598-017-09536-z

151. Rogers LC, Lavery LA, Joseph WS, Armstrong DG. All feet on deck-the role of podiatry during the COVID-19 pandemic: preventing hospitalizations in an overburdened healthcare system, reducing amputation and death in people with diabetes. $J \mathrm{Am}$ Podiatr Med Assoc. 2020. doi:10.7547/20-051

152. Epidemiology Working Group for NCIP Epidemic Response, Chinese Center for Disease Control and Prevention. [The epidemiological characteristics of an outbreak of 2019 novel coronavirus diseases (COVID-19) in China]. Zhonghua Liu Xing Bing Xue Za Zhi. 2020;41(2):145-151. [Chinese]. doi:10.3760/cma.j. issn.0254-6450.2020.02.003

153. Liu J, Liu Y, Xiang P, et al. Neutrophil-to-lymphocyte ratio predicts severe illness patients with 2019 novel coronavirus in the early stage. J Translat Med. 2020;18:1-12. doi:10.1101/ 2020.02.10.20021584

154. Chen T, Wu DI, Chen H, et al. Clinical characteristics of 113 deceased patients with coronavirus disease 2019: retrospective study. BMJ. 2020;368. doi:10.1136/bmj.m1091

155. Zhang J, Dong X, Cao YY, et al. Clinical characteristics of 140 patients infected with SARS-CoV-2 in Wuhan, China. Allergy. 2020;75:1730-1741. doi:10.1111/all.14238

156. Chen N, Zhou M, Dong X, et al. Epidemiological and clinical characteristics of 99 cases of 2019 novel coronavirus pneumonia in Wuhan, China: a descriptive study. Lancet. 2020;395 (10223):507-513. doi:10.1016/S0140-6736(20)30211-7

157. Yang $\mathrm{X}, \mathrm{Yu} \mathrm{Y,} \mathrm{Xu} \mathrm{J}$, et al. Clinical course and outcomes of critically ill patients with SARS-CoV-2 pneumonia in Wuhan, China: a single-centered, retrospective, observational study. Lancet Respir Med. 2020;8(5):475-481. doi:10.1016/S22132600(20)30079-5

158. Wu C, Chen X, Cai Y, et al. Risk factors associated with acute respiratory distress syndrome and death in patients with coronavirus disease 2019 pneumonia in Wuhan, China. JAMA Intern Med. 2020;180(7):934. doi:10.1001/jamainternmed.2020.0994

159. Liu K, Fang YY, Deng Y, et al. Clinical characteristics of novel coronavirus cases in tertiary hospitals in Hubei Province. Chin Med J. 2020;133(9):1025-1031. doi:10.1097/CM9.000000000 0000744

160. Guo T, Fan Y, Chen M, et al. Cardiovascular implications of fatal outcomes of patients with coronavirus disease 2019 (COVID-19). JAMA Cardiol. 2020;5(7):811. doi:10.1001/jamacardio.20 20.1017

161. CDCMMWR. Preliminary estimates of the prevalence of selected underlying health conditions among patients with coronavirus disease 2019 - United States, February 12-March 28, 2020. MMWR Morb Mortal Wkly Rep. 69;2020. doi:10.15585/mmwr. $\mathrm{mm} 6913 \mathrm{e} 2$ 
162. Bhatraju PK, Ghassemieh BJ, Nichols M, et al. Covid-19 in critically ill patients in the Seattle Region - case series. $N$ Engl $J$ Med. 2020;382(21):2012-2022. doi:10.1056/ NEJMoa2004500
163. Pal R, Bhansali A. COVID-19, diabetes mellitus and ACE2: the conundrum. Diabetes Res Clin Pract. 2020;162:108132. doi:10.1016/j.diabres.2020.108132

\section{Publish your work in this journal}

Diabetes, Metabolic Syndrome and Obesity: Targets and Therapy is an international, peer-reviewed open-access journal committed to the rapid publication of the latest laboratory and clinical findings in the fields of diabetes, metabolic syndrome and obesity research. Original research, review, case reports, hypothesis formation, expert opinion and commentaries are all considered for publication. The manuscript management system is completely online and includes a very quick and fair peer-review system, which is all easy to use. Visit http://www.dovepress.com/testimonials.php to read real quotes from published authors.

Submit your manuscript here: https://www.dovepress.com/diabetes-metabolic-syndrome-and-obesity-targets-and-therapy-journal 